\title{
Developing Critical Thinking in OT Education: Effectiveness of a Fishbowl Approach
}

Stephanie L. de Sam Lazaro

St. Catherine University

Bonnie R. W. Riley

St. Catherine University

Follow this and additional works at: https://encompass.eku.edu/jote

Part of the Occupational Therapy Commons

\section{Recommended Citation}

de Sam Lazaro, S. L., \& Riley, B. R. (2019). Developing Critical Thinking in OT Education: Effectiveness of a Fishbowl Approach. Journal of Occupational Therapy Education, 3 (2). https://doi.org/10.26681/jote.2019.030201

This Original Research is brought to you for free and open access by the Journals at Encompass. It has been accepted for inclusion in Journal of Occupational Therapy Education by an authorized editor of Encompass. For more information, please contact Linda.Sizemore@eku.edu. 


\title{
Developing Critical Thinking in OT Education: Effectiveness of a Fishbowl Approach
}

\begin{abstract}
This paper explores the effectiveness of peer assisted learning on developing critical thinking skills in an occupational therapy graduate course. The use of peer teaching strategies, including a Fishbowl discussion and case-based problem solving, were compared to a faculty-led lecture approach to determine which approach best prepared student critical thinking. Participants included 115 first year graduate occupational therapy students. No statistically significant differences were noted in student ability to express knowledge, comprehension, and application of information. However, statistically significant differences were noted on graduate student ability to analyze, synthesize, and evaluate using newly learned information when peer teaching strategies were used in the classroom. Therefore, the authors concluded peer assisted learning approaches may support better integration of knowledge at higher levels of Bloom's knowledge for critical thinking than traditional faculty-led teaching approaches.
\end{abstract}

\section{Keywords}

Peer teaching, fishbowl approach, case-based problem solving

\section{Creative Commons License} (c) (1) $\Theta$

This work is licensed under a Creative Commons Attribution-Noncommercial-No Derivative Works 4.0 License.

\section{Acknowledgements}

We acknowledge Dr. Paula Rabaey's contribution to the development of the Fishbowl and case-based activities for use in the classroom and for being a third blind coder of taxonomy level for the exam questions used to validate the results. 


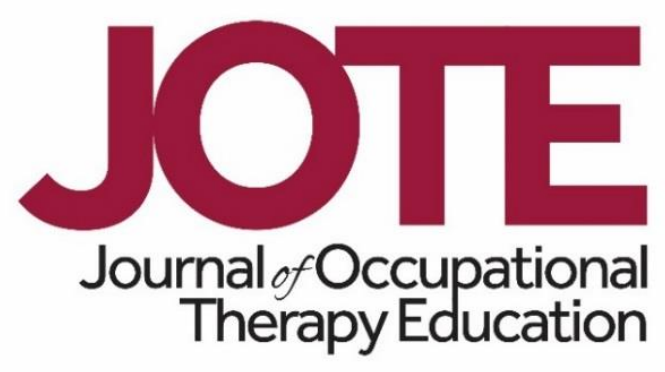

Volume 3, Issue 2

\title{
Developing Critical Thinking in OT Education:
}

Effectiveness of a Fishbowl Approach

Stephanie L. de Sam Lazaro, OTD, OTR/L and Bonnie R. W. Riley, OTD, OTR/L

St. Catherine University

United States

\begin{abstract}
This paper explores the effectiveness of peer assisted learning on developing critical thinking skills in an occupational therapy graduate course. The use of peer teaching strategies, including a Fishbowl discussion and case-based problem solving, were compared to a faculty-led lecture approach to determine which approach best prepared student critical thinking. Participants included 115 first year graduate occupational therapy students. No statistically significant differences were noted in student ability to express knowledge, comprehension, and application of information. However, statistically significant differences were noted on graduate student ability to analyze, synthesize, and evaluate using newly learned information when peer teaching strategies were used in the classroom. Therefore, the authors concluded peer assisted learning approaches may support better integration of knowledge at higher levels of Bloom's knowledge for critical thinking than traditional faculty-led teaching approaches.
\end{abstract}

\section{BACKGROUND}

Critical thinking, including the ability to solve problems and apply effective interventions, is essential for the occupational therapist. Understanding the theory underpinning practice is an important skill for students to build their critical thinking as an occupational therapist. However, merely understanding the concept of a theory is not sufficient as students will need to be able to apply and analyze different theories as they evaluate clinical decisions and design interventions. This preparation is important as students and novice occupational therapists continue to build their understanding of theories (Nash \& Mitchell, 2017). Therefore, the need to evaluate and create interventions using theory as a foundation requires a teaching strategy that helps students connect the dots between theory knowledge and how theory drives the work of the occupational therapy practitioner with clients. When considering this teaching objective, it is important to 
select an engaging and demanding teaching strategy to foster the students' ability to appreciate and critique the relevance of theory to their work as they develop professional critical thinking. Creating opportunities for students to solve problems and debate how they have solved the problem offers the opportunity for challenging learners to evaluate their knowledge and create solutions with this knowledge (Nkhoma, Lam, Richardson, Kam, \& Lau, 2016).

When reflecting on instructor experiences in one graduate occupational therapy program, it seemed the approach used to teach students occupational therapy theory was not providing the opportunity for students to interact with and relate to content. When reviewing how graduate students in the program were learning occupational therapy theories, it became apparent the students were struggling with integrating their learning into activities later in the curriculum. In fact, an honest graduate student in the program admitted the table completed in class to organize and differentiate theories was thrown out in the trash. Vygotsky's zone of proximal development supports that when students are able to personally relate to concepts, they are more prepared to recall and rely on this information in new situations (Bishop \& Verleger, 2013; Bryan, Kreuter, \& Brownson, 2009). Critical thinking, or the ability to transform knowledge into practice, is essential for quality care and a professional responsibility (Raymond, Profetto-McGrath, Myrick, \& Strean, 2017). To increase the students' critical thinking, other approaches were considered to force the students in this program into models of learning that emphasize self-direction in the learning process to encourage critical thinking and synthesis of information for solving problems (Bryan et al., 2009; Wells, Warelow, \& Jackson, 2009). How critical thinking is developed has not been widely measured; however, it appears the learning context is important in developing critical thinking among students (Raymond et al., 2017). There are several teaching strategies to overcome the challenge of developing critical thinking skills, which may benefit occupational therapy students.

A flipped classroom model supports student preparation for active engagement with other peers and the instructor. A flipped classroom approach requires students to prepare material before class in order to apply during class activities. Since evidence shows learning from lectures occurs equally between traditional in-class lectures and online lectures (Murray, McCallum, \& Petrosino, 2014), there is the opportunity for using class time for more engaging, interactive learning activities. This offers the opportunity for the instructor to scaffold student understanding of complex professional concepts, such as professional theories, while the student shares their knowledge acquired in preparation for the class. Ratta (2015) noted improved scores on the final examination when using collaborative peer learning in a flipped classroom. Peer teaching relies on social constructivism to support the critical thinking of learners (Stigmar, 2016). Peer teaching is sometimes referred to as peer mentoring or peer tutoring and is when peers support each another in acquiring knowledge and skills (Brannagan et al., 2013). Collaborative learning occurs when students work together to achieve a learning goal. Flipped classrooms create the space for peer-assisted learning, which includes peer teaching and collaborative learning approaches such as Fishbowl discussions and case-based problem solving (Bishop \& Verleger, 2013). 
One approach for in-class learning using peer teaching and collaborative peer learning is a Fishbowl discussion. Fishbowls are a teaching approach that allow students to participate in a structured class discussion with ongoing peer feedback as knowledge is translated. During a Fishbowl discussion, a small group of students initiate the conversation in collaborative learning while on-looking students provide feedback and engage in peer teaching. The purpose of a Fishbowl is to provide students the opportunity to construct meaning in a way that becomes personal to them (Cummings, 2015). Additionally, case-based discussions can further enhance students' critical thinking and ability to apply concepts in real life situations. The use of cases in learning increases student interest and develops knowledge for critical thinking (Trommelen, Karpinski, \& Chauvin, 2017). The structure for integrating case-based discussions into learning seems important. Johnson (2011) observed higher student course evaluations for active learning approaches such as Fishbowls and group brainstorming.

It therefore seems likely a flipped classroom employing a Fishbowl approach using case-based discussions offers great potential for building occupational therapy students' critical thinking skills. However, there is limited research specific to active engagement practices in occupational therapy education. The students in this study participated in a Fishbowl approach with peer teaching through student- led case-based discussion and reflection. This research project compared the difference between a traditional textbook/lecture teaching model to an active learning approach in a professional course in occupational therapy education.

The purpose of the research was to compare the effectiveness of a collaborative Fishbowl approach with peer teaching for learning theoretical concepts of pediatric occupational therapy to faculty led lecture and factual based teaching methods. Considering the existing evidence, it was hypothesized students who were taught using peer assisted learning via the Fishbowl approach with case-based discussions would demonstrate increased ability to apply learning.

\section{METHODS}

This study was designed to conduct a post hoc analysis of the two different teaching approaches used to instruct graduate occupational therapy students following approval from the Institutional Review Board committee. Exam responses and scores were compared between two groups of students who were taught theoretical pediatric occupational therapy theories with different instruction methods. The data used in the study was from an exam students took as part of a credit bearing course.

\section{Participants}

The target population was first year graduate occupational therapy students. These students were enrolled in a 7-week, 3-credit graduate level course. The course was taught using both online and face-to-face learning methods for all cohorts included in the study; students were in face-to-face sessions the equivalent of 6 hours each week over the course of the 7-week semester. Students were divided into two groups depending on when they took the course/the instruction method used. The first group of students were instructed using faculty-led factual based lectures $(n=57)$ while 
completing a table (study aid) to organize the information shared in class. The second group of students were taught the same content through case-based peer teaching $(\mathrm{n}=58)$ using Fishbowl discussions in class and abbreviated case descriptions using the occupational profile template (AOTA, 2017). The expectations for out of class work and preparation were the same for both groups (12 hours a week of out of class work).

\section{Teaching Methods}

Faculty-led teaching group. Students in this group were exposed to content on theories, models, and frames of reference used in pediatric occupational therapy practice through traditional pedagogical methods. Some of these methods included reading textbook and journal articles, in-class lectures, a few video lectures, and large group discussions of sample cases. Students were required to work in pairs to complete a "theory to practice grid" assignment. Within this assignment, students were required to (1) identify the authors of the model or frame of reference; (2) key aspects of the model or frame of reference, including strengths and weaknesses; (3) three assessment tools that aligned with the key principles of the model or frame of reference; (4) two questions to ask a client or caregiver from the perspective of the model or frame of reference; and (5) two intervention strategies from the perspective of the model or frame of reference. Students completed these grids/study aids at two intervals in the course; half of the targeted models and frames of reference were due at the midterm point in the course and the remainder were due at the end of the course.

Peer-teaching group. Students in this group were exposed to lecture information similar to the Faculty-Led Teaching Group; however, the lecture was provided in the format of pre-recorded video lectures available in the online class platform and not in the form of in-class lecture. The same models and frames of reference were taught to this group as with the Faculty-Led Teaching Group. Students were provided directions for participating in the Fishbowl discussion and tools for participating in a case-based discussion (all students reviewed a brief paragraph of case information and watched a video of an intervention session or evaluation session with a client). After reading their assigned case, reviewing the video, and completing the readings/pre-recorded lectures on the models and frames of reference, a group of six to nine students were required to participate in a facilitated discussion using a Fishbowl approach in which they applied theoretical concepts to their assigned case. The faculty member facilitated each discussion with four guiding questions. Students were expected to come prepared to discuss key information relevant to the case from the lens of their assigned model or frame of reference and could include ways to approach evaluation and intervention planning, methods for supporting occupational participation, and methods for collaborating with clients, caregivers, and interdisciplinary team members. Students were expected to demonstrate collaborative discussion skills, scholarship to support their knowledge, acceptance of other perspectives, and the ability to express opinions in a professional manner. For example, students were encouraged to question one another's viewpoints to discuss key similarities and differences between the different models and frames of reference as they applied to a case. Meanwhile, other students not in the group hosting the discussion were on the outside offering written feedback. 
Each discussion lasted 30 - 45 minutes and was followed by debriefing and summary with the entire class. Four Fishbowl discussions were included during the course and three different models of practice or frames of reference were included in each Fishbowl discussion.

\section{Analysis}

Student responses from seven multiple choice and nine short answer exam questions were considered for data to analyze the effectiveness of the Fishbowl approach with case-based discussion (see Table 1). Each instructor graded the exam questions for the course sections that they taught using a rubric to support consistency in grading across all class sections. Each exam question was mapped to one of the six categories of cognitive skills (knowledge, comprehension, application, analysis, synthesis, evaluation) from the Bloom's Taxonomy for comparative analysis of student outcomes data (Adams, 2015). Both authors coded each question individually, in addition to a third faculty member in the department familiar with the exam questions but not the approach of the study. Both authors discussed and reached agreement to increase the reliability and validity of the results of the coding process.

De-identified exam data was exported into an Excel spreadsheet from the course's online learning platform. The data exported was linked to question numbers. Questions were then organized by question type and Bloom's level. Exam data was then analyzed using SPSS Version 23 and Chi-Square analysis.

Table 1

Exam Question Mapping to Bloom's Cognitive Skills Categories

\begin{tabular}{lll}
$\begin{array}{l}\text { Type of } \\
\text { Question }\end{array}$ & Question Content & $\begin{array}{l}\text { Bloom's } \\
\text { Category }\end{array}$ \\
\hline Multiple & 1. Which approach focuses on manually guiding and & Knowledge \\
Choice & handling a child while the child performs an activity? &
\end{tabular}

2. Which statement most closely describes the practice of Knowledge sensory integration intervention?

3. Which theory refers to the interaction and cooperation Knowledge of many systems as key to children's learning?

4. The OT provides a toddler with a corner seat that helps Application provide stability, enabling the child to reach more accurately for toys. Which frame of reference is the therapist using to guide treatment in this instance?

5. Ayres sensory integration theory emphasizes the following "proximal senses"?

Knowledge 


\begin{tabular}{ll}
$\begin{array}{l}\text { Type of } \\
\text { Question }\end{array}$ & Question Content \\
\hline $\begin{array}{l}\text { 6. The biomechanical frame of reference is most likely to } \\
\text { be used in assessing and intervening in hand skill } \\
\text { problems in children with which of the following types of } \\
\text { problems? }\end{array}$
\end{tabular}

7. Which of the following is NOT an assumption of the NDT frame of reference?

Short 1. Name two main goals of Biomechanical Frame of Answer Reference for positioning for children.

2. As the occupational therapist, you recently initiate services with a 10 year old girl with spina bifida. Her lesion is at the T1 level, and she uses a motorized wheelchair. She has difficulty with lower extremity dressing and the dressing involved in catheterization. Using the dynamic systems model, identify 3 variables that would likely affect dressing goals. Justify your answer.

3. [Case provided] What information supports a sensory integrative dysfunction?

4. [Case provided] What specific behaviors suggest dyspraxia?

5. [Case provided] List an observation that you would use to confirm the diagnosis of dyspraxia.

6. [Case provided] From a motor skill acquisition FOR perspective, what other factors might be interfering with Fiona's movement?

7. [Case provided] a. Using a model of practice, describe Bobby's strengths and weaknesses? (Name the model of practice)

8. [Case provided] How might Bobby's motor skills be interfering with his school performance?

9. [Case provided] What frame of reference(s) would you choose to use when working with Bobby and WHY?
Bloom's

Category

Application

Knowledge

Knowledge

Synthesize

Comprehend

Application

Analyze

Analyze

Application

Evaluate

Synthesize 


\section{RESULTS}

Test scores were collected from 115 students including 57 students in the Faculty-Led Teaching Group and 58 students in the Peer-Teaching Group.

Multiple choice (MC) items 1, 2, 3, 5, and 7, and short answer (SA) items 1 and 3 were coded at the knowledge or comprehension levels of Bloom's taxonomy. For MC5, all students in the Faulty-Led Teaching Group answered them correctly with $96.6 \%$ of students in the Peer-Teaching group answering it correctly. For MC2 and MC3, all students in both groups answered the items correctly. For MC7 and SA3, a greater percentage of students in the Faculty-Led Teaching Group answered the item correctly than in the Peer-Teaching Group and for SA1, a greater percentage of students in the Peer-Teaching Group answered the item correctly than those in the Faculty-Led Teaching Group. However, there were no statistically significant differences between the two groups on any of these items. See Table 2.

Table 2

Exam Question Accuracy for Knowledge and Comprehension

\begin{tabular}{lllll}
\hline Question Item & Cohort & $\begin{array}{l}\text { Partial/No } \\
\text { Credit }\end{array}$ & Full Credit & $\begin{array}{c}\text { Pearson's Chi- } \\
\text { Square p-value }\end{array}$ \\
\hline Multiple Choice 2 & Faculty Led & $0.0 \%$ & $100 \%$ & \\
& Peer Teaching & $0.0 \%$ & $100 \%$ & $\mathrm{~N} / \mathrm{A}$ \\
Multiple Choice 3 & Faculty Led & $0.0 \%$ & $100 \%$ & \\
& Peer Teaching & $0.0 \%$ & $100 \%$ & $\mathrm{~N} / \mathrm{A}$ \\
Multiple Choice 5 & Faculty Led & $0.0 \%$ & $100 \%$ & \\
& Peer Teaching & $3.4 \%$ & $96.6 \%$ & .157 \\
Multiple Choice 7 & Faculty Led & $45.6 \%$ & $54.4 \%$ & \\
& Peer Teaching & $56.9 \%$ & $43.1 \%$ & .226 \\
Short Answer 1 & Faculty Led & $29.8 \%$ & $70.2 \%$ & \\
& Peer Teaching & $22.4 \%$ & $77.6 \%$ & .366 \\
Short Answer 3 & Faculty Led & $5.3 \%$ & $94.7 \%$ & \\
& Peer Teaching & $10.3 \%$ & $89.7 \%$ & .310 \\
\hline
\end{tabular}

MC 4, MC6, SA4, and SA7 were coded at the application level. For MC6, SA4, and SA7, students in the Faculty-Led Teaching Group performed better than students in the Peer-Teaching Group. The opposite was true for MC4. However, again, there were no statistically significant differences between the two groups on any of these items and $74 \%$ or more students answered all of these items correctly. See Table 3. 
Table 3

Exam Question Accuracy for Application

\begin{tabular}{lllll}
\hline Question Item & Cohort & $\begin{array}{l}\text { Partial/No } \\
\text { Credit }\end{array}$ & Full Credit & $\begin{array}{l}\text { Pearson's Chi- } \\
\text { Square p-value }\end{array}$ \\
\hline Multiple Choice 4 & Faculty Led & $12.3 \%$ & $87.7 \%$ & \\
& Peer Teaching & $6.9 \%$ & $93.1 \%$ & .326 \\
Multiple Choice 6 6 & Faculty Led & $7.0 \%$ & $93.0 \%$ & \\
& Peer Teaching & $12.1 \%$ & $87.9 \%$ & .357 \\
Short Answer 4 & Faculty Led & $0.0 \%$ & $100 \%$ & \\
& Peer Teaching & $1.7 \%$ & $98.3 \%$ & .319 \\
Short Answer 7 & Faculty Led & $15.8 \%$ & $84.2 \%$ & \\
& Peer Teaching & $25.9 \%$ & $74.1 \%$ & .184 \\
\hline
\end{tabular}

SA5 and SA6 were coded at the analyze level. SA2 and SA9 were coded at the synthesize level. SA8 was coded at the evaluate level. For SA5, the Faculty-Led Teaching Group performed better than the Peer-Teaching Group, but no statistically significant difference in performance between the groups was noted. For all remaining items (SA2, SA6, SA8, and SA9), the Peer-Teaching Group performed better than the Faculty-Led Group with statistically significant differences found at $p=.036$ (SA6), $\mathrm{p}=0.32$ (SA9), $\mathrm{p}=.009$ (SA2), and $\mathrm{p}=.001$ (SA8). See Table 4 and Figure 1.

Table 4

Faculty-Led Teaching Compared to Peer-Teaching: Analysis, Synthesis, and Evaluation

\begin{tabular}{lllll}
\hline Question Item & Cohort & $\begin{array}{l}\text { Partial/No } \\
\text { Credit }\end{array}$ & Full Credit & $\begin{array}{c}\text { Pearson's Chi- } \\
\text { Square p-value }\end{array}$ \\
\hline Short Answer 2 & Faculty Led & $36.8 \%$ & $63.2 \%$ & \\
& Peer Teaching & $15.5 \%$ & $84.5 \%$ & .009 \\
Short Answer 5 & Faculty Led & $3.5 \%$ & $96.5 \%$ & \\
& Peer Teaching & $10.3 \%$ & $89.7 \%$ & .150 \\
Short Answer 6 & Faculty Led & $17.5 \%$ & $82.5 \%$ & \\
& Peer Teaching & $5.2 \%$ & $94.8 \%$ & .036 \\
Short Answer 8 & Faculty Led & $28.1 \%$ & $71.9 \%$ & \\
& Peer Teaching & $5.2 \%$ & $94.8 \%$ & .001 \\
Short Answer 9 & Faculty Led & $36.8 \%$ & $63.2 \%$ & \\
& Peer Teaching & $19.0 \%$ & $81.0 \%$ & .032 \\
& & & & \\
\hline
\end{tabular}




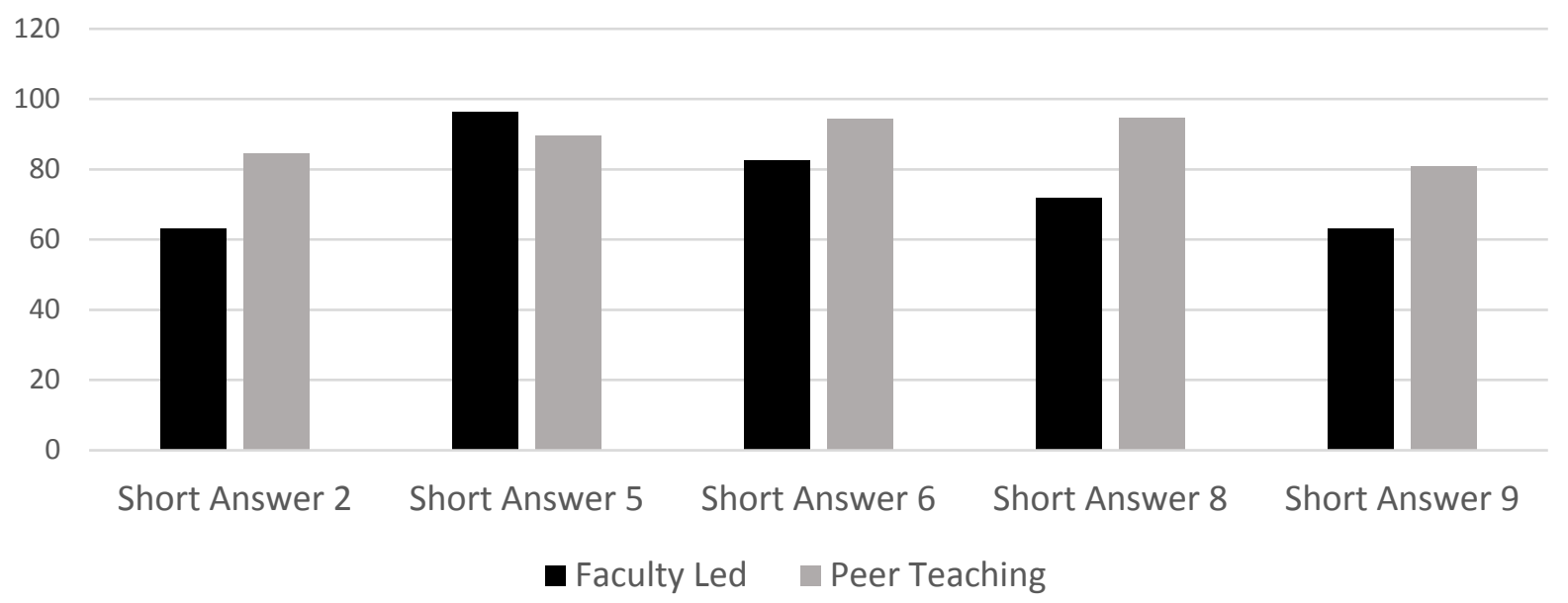

Figure 1. Faculty-led teaching compared to peer-teaching: analysis, synthesis, and evaluation. For all but Short Answer 5 a statistically significant difference was noted between the two groups with the peer teaching group performing statistically significantly higher.

\section{DISCUSSION}

Based on the results of this study, test questions that were at the knowledge, comprehension, and application level suggest students in both teaching groups performed at similar levels with no statistically significant differences between groups. For more complex exam items requiring critical thinking skills of analysis, synthesis, and evaluation, students in the Peer-Teaching Group generally outperformed their peers at statistically significant levels of difference. A general trend of growth in the degree of statistically significant difference was also noted as the learning taxonomy increased from analyze to synthesize to evaluate. For instance, the item at the evaluation level noted a statistically significant difference at $p=.001$ whereas the item that showed statistically significant difference at the analysis level was at $p=.036$. It is especially important to note that the case items were at a lower Bloom's category (SA3 and SA4) and other parts were at higher Bloom's categories (SA5 and SA6); students performed similarly in both groups for the lower category items and showed more discrepancy in the higher level item. This finding supports that foundational knowledge influences higher level critical thinking skills (Raymond et al., 2017). In addition, items which included multiple parts where a portion of the points for the item were linked to a direction or question at the knowledge and comprehension level (SA2 and SA9), students in the Faculty-Led Group had a much larger range of points (1.0-3.0 points for SA2 and 1.0-2.0 for SA9), whereas the students in the Peer-Teaching Group had a smaller range (2.0-3.0 for SA2 and 1.5-2.0 for SA9).

There are two valuable considerations from these findings. First, either faculty-led lecture or the Fishbowl discussion approach method appears to support students' learning of theoretical knowledge at similar levels for Bloom's learning categories of knowledge, comprehension, and application. However, peer-teaching methods (in particular Fishbowl discussions with case-based approach) for teaching theoretical knowledge supports students in developing stronger critical thinking skills at the 
analyze, synthesize, and evaluate levels of integration of learning. This confirms other findings that the use of active learning processes can support student learning at higher Bloom's cognitive levels (Khan, Egbue, Palkie, \& Madden, 2017). Exploring peer teaching methods and processes for student engagement with the content, including case based application, appears to support students in integrating knowledge from theoretical backgrounds into clinical application. This is highly important for two reasons. First, students are requesting different types of learning experiences and want to be engaged in their learning. While there are many different learning models that take a different approach to how self-directed learning should occur, many include the role of the teacher or educator as a facilitator or guide to support the progression of the learning of the student while allowing the student to take more control of the learning over time (Bryan et al., 2009; Grow, 1994; Walker \& Leary, 2009; Wells et al., 2009). Secondly, expectations for the education of graduate students in occupational therapy require faculty to support students in analyzing, synthesizing, and evaluating the models and theories they are using in practice. These expectations for students require reconsideration of teaching methods to best meet those expectations.

Therefore, reconsideration of teaching methods coincides with the evaluation of assessment methods used. This study revealed the necessity of also examining how we assess student learning. There were 16 exam items included in the data analysis process. Only five of those items fell into the higher categories of Bloom's (analyze, synthesize, and evaluate), whereas the vast majority, 11 items, were in the lower levels, knowledge, comprehension, and application, with the highest percentage of any category in the knowledge arena. Occupational therapy instructors should examine the types of questions asked on examinations as well as the methods for assessing learning, while considering how assessments align with needed professional practice skills. Through this process, the authors began to consider if the exam questions were written in a manner that was a good measure of the content learned in preparation for application during professional practice.

\section{Limitations}

Two different faculty co-taught and facilitated the learning of the two participant groups. While these two faculty worked collaboratively on all course development, learning activities, assignments, and examinations, their teaching style may vary from session to session which could have an impact on the results. These two faculty were individually responsible for grading the short answer items; a rubric was used and the two faculty consulted with one another for consistency of grading. The small number of students in each group limits the generalizability of information. Although the preparation and out of class work expectations were the same for both groups, the specific amount of out of class preparation was not measured; if class preparation was significantly different, it could have impacted the results. Additionally, the exam questions were used as written; however, the exam questions may have been limited in measuring how the content was learned using the two different teaching strategies. The ability to use the learning over time could also have been considered with an additional data measure later in the curriculum. Finally, there is potential for a Type I error due to the number of inferential tests performed during analysis. 


\section{CONCLUSION}

It is important to consider the value of the teaching methods used to support students' learning. There is evidence to explore more peer-assisted learning activities with the faculty as a guide when critical thinking for professional practice is desired. Faculty also need to consider the assessment metrics used to evaluate the learning of students when preparing the students for professional practice. It is unknown at this time, the current best metrics for occupational therapy education to measure student performance at each Bloom's taxonomy level. As courses are developed and redesigned, occupational therapy educators should note how content is scaffolded within the course (and between courses in the curriculum) to support student knowledge building and knowledge translation.

\section{References}

Adams, N. E. (2015). Bloom's taxonomy of cognitive learning objectives. Journal of the Medical Library Association, 103(3), 152-153. https://doi.org/10.3163/1536-5050.103.3.010

American Occupational Therapy Association. (2017). AOTA occupational profile template [pdf document]. Retrieved from https://www.aota.org/ /media/Corporate/Files/Practice/Manage/Documentation/A OTA-Occupational-Profile-Template.pdf

Bishop, J. L., \& Verleger, M. A. (2013, June). The flipped classroom: A survey of the research [pdf document]. In ASEE national conference proceedings, Atlanta, GA (Vol. 30, No. 9, pp. 1-18). Retrieved from https://www.asee.org/public/conferences/20/papers/6219/download

Brannagan, K. B., Dellingger, A., Thomas, J., Mitchell, D., Lewis-Trabeaux, S., \& Dupre, S. (2013). Impact of peer teaching on nursing students: Perceptions of learning environment, self-efficacy, and knowledge. Nurse Education Today, 33(11), 1440-1447. https://doi.org/10.1016/j.nedt.2912.11.018

Bryan, R. L., Kreuter, M. W., \& Brownson, R. C. (2009). Integrating adult learning principles into training for public health practice. Health Promotion Practice 10(4), 557-563. https://doi.org/10.1177/1524839907308117

Cummings, C. (2015). Rethinking the fishbowl discussion strategy: A mechanism to construct meaning and foster critical thinking and communication skills through student dialogue. Journal of Health Education Teaching Techniques, 2(3). Retrieved from http://jhetonline.com/

Grow, G. (1994). In defense of the staged self-directed learning model. Adult Education Quarterly, 44(2), 109-114. https://doi.org/10.1177/074171369404400206

Johnson, P. A. (2011). Actively pursuing knowledge in the college classroom. Journal of College Teaching \& Learning, 8(6), 17-30. https://doi.org/10.19030/tlc.v8i6.4279

Khan, A., Egbue, O., Palkie, B., \& Madden, J. (2017). Active learning: Engaging students to maximize learning in an online course. Electronic Journal of $e$ learning, 15(2), 107-115. Retrieved from www.ejei.org

Murray, L., McCallum, C., \& Petrosino, C. (2014). Flipping the classroom experience: A comparison of online learning to traditional lecture. Journal of Physical Therapy Education, 28(3), 35-41. https://doi.org/10.1097/00001416-201407000-00006 
Nash, B., \& Mitchell, A. (2017). Longitudinal study of changes in occupational therapy students' perspectives on frame of reference. American Journal of Occupational Therapy, 71. 7105230010p1-7105230010p7. https://doi.org/10.5014/ajot.2017.024455

Nkhoma, M., Lam, T., Richardson, J., Kam, K., \& Lau, K. H. (2016). Developing casebased learning activities based on the revised Bloom's taxonomy. Proceedings of Informing Science \& IT Education Conference (In SITE) 2016, 85-93. Retrieved from http://www.informingscience.org/Publications/3496

Ratta, C. B. (2015). Flipping the classroom with team-based learning in undergraduate nursing education. Nurse Educator, 40(2), 71-74. https://doi.org/10.1097/NNE.0000000000000112

Raymond, C., Profetto-McGrath, J., Myrick, F., \& Strean, W. B. (2017). An integrative review of the concealed connection: Nurse educators' critical thinking. Journal of Nursing Education, 56(11), 648-654. https://doi.org/10.3928/01484834-20171020-03

Stigmar, M. (2016). Peer-to-peer teaching in higher education: A critical literature review. Mentoring \& Tutoring: Partnership in Learning, 24(2), 124-136. https://doi.org/10.1080/13611267.2016.1178963

Trommelen, R., Karpinski, A., \& Chauvin, S. (2017). Impact of case-based learning and reflection on abilities in physical therapy students. Journal of Physical Therapy Education, 31, 21-30. https://doi.org/10.1097/00001416-201731010-00006

Walker, A., \& Leary, H. (2009). A problem-based learning meta-analysis: Differences across problem types, implementation types, disciplines, and assessment levels. Interdisciplinary Journal of Problem-Based Learning, 3(1), 6-28. https://doi.org/10.7771/1541-5015.1061

Wells, S. H., Warelow, P. J., \& Jackson, K. L. (2009). Problem-based learning (PBL): A conundrum. Contemporary Nurse 33(2), 191-201. https://doi.org/10.5172/conu.2009.33.2.191 